\title{
RELAÇÕES ENTRE TRANSPIRAÇÃO MÁXIMA, EVAPOTRANSPIRAÇÃO DE REFERÊNCIA E ÁREA FOLIAR EM QUATRO VARIEDADES DE MANGUEIRA ${ }^{1}$
}

\author{
GREICE XIMENA SANTOS OLIVEIRA², MAURÍCIO ANTONIO COELHOFILHO ${ }^{3}$, \\ FRANCISCO ADRIANODECARVALHO PEREIRA ${ }^{4}$,EUGÊNIOFERREIRACOELHO ${ }^{3}$, \\ VITAL PEDRO DA SILVAPAZ ${ }^{4}$, MANOEL TEIXEIRA DECASTRO NETO 5
}

RESUMO- Nas condições edafoclimáticas de Cruz da Almas - BA, na Embrapa Mandioca e Fruticultura Tropical, foi realizado um estudo no qual se relacionou a transpiração máxima (Litros $\mathrm{m}^{-2}$ folha/dia ${ }^{-1}$ ) de quatro variedades de mangueira (Tommy Atkins, Palmer, Haden e Van Dyke, com áreas foliares totais de 14; 8; 33 e $12 \mathrm{~m}^{2}$, respectivamente) com a evapotranspiração de referência (ETo). A transpiração das plantas (L $\mathrm{dia}^{-1}$ ) foi estimada por meio de sensores que realizam o balanço de calor no caule (modelos SAG13; SGB9; SGB16; SGB19 e SGB25, Dynamax Inc.) dispostos nos sentidos norte (N), sul (S), leste (E), oeste (W) e centro $(\mathrm{C})$ de cada planta. A transpiração por unidade de área foliar $\left(\mathrm{L} \mathrm{m}^{-2}\right.$ folha dia $\left.{ }^{-1}\right)$ variou em média de 1,58 ao longo do período estudado, e linearmente com o aumento da área foliar total da planta, independentemente da variedade estudada. A transpiração (Litros $\mathrm{m}^{-2}$ folha/dia ${ }^{-1}$ ) variou de 0,36 a 3,00, dependendo da demanda atmosférica. A transpiração máxima ( $\mathrm{T}$ ) das quatro variedades de mangueira (Litros $\mathrm{m}^{-2}$ folha/dia ${ }^{-1}$ ) relacionouse linearmente com a ETo $\left(\mathrm{T}=0,44 . \mathrm{ETo} ; \mathrm{r}^{2}=0,78\right)$, sendo um excelente subsídio para o manejo de irrigação por gotejamento nesta cultura.

Termos de indexação: manga, fluxo de seiva, uso de água.

\section{MAXIMUM TRANSPIRATION, REFERENCE EVAPOTRANSPIRATION AND LEAF AREA RELATIONSHIPS FOR SOME MANGO CULTIVARS}

\begin{abstract}
A study relating maximum transpiration $\left(\mathrm{L} \mathrm{m}^{-2}\right.$ leaf day $\left.{ }^{-1}\right)$ to reference evapotranspiration (ETo) for four mango cultivars (Tommy Atkins, Palmer, Haden and Van Dyke, with $14 \mathrm{~m}^{2}, 8 \mathrm{~m}^{2}, 33 \mathrm{~m}^{2}$ and 12 $\mathrm{m}^{2}$ of leaf area, respectively) was carried out at Embrapa Cassava and Tropical Fruits, in the conditions of Cruz da Almas-BA. Plant transpiration (L. day ${ }^{-1}$ ) was estimated by heat balance sensors that were installed on the shoots (models SAG13; SGB9; SGB16; SGB19 e SGB25, Dynamax Inc.). The sensors were installed to the North (N), South (S), East (E), West (W) and Center(C) of each plant. The transpiration per unity leaf area $\left(\mathrm{L} . \mathrm{m}^{-2}\right.$.day $\left.{ }^{-1}\right)$ varied about 1.58 in average along the studied period and it also varied linearly with the increase in total leaf area, regardless the studied variety. Transpiration (Liters $\mathrm{m}^{-2}$ leaf area day ${ }^{-1}$ ) varied from 0.36 to 3.00 , according to the atmospheric demand. The maximum transpiration $(\mathrm{T})$ of the four mango varieties $\left(\right.$ Liters $\mathrm{m}^{-2}$ leaf area day $\left.{ }^{-1}\right)$ linearly related to $\mathrm{ETo}\left(\mathrm{T}=0.44 . \mathrm{ETo} ; \mathrm{r}^{2}=0.78\right)$, performing as a reasonable tool for mango crop drip irrigation management.
\end{abstract}

Index terms: mango, sap flow, water use.

\footnotetext{
${ }^{1}$ (Trabalho 049-08). Recebido em: 04-03-2008. Aceito para publicação em: 09-12-2008.Parte da dissertação de mestrado da primeira autora.

${ }^{2}$ Doutoranda Física do Ambiente Agrícola, Depto. de Ciências Exatas, ESALQ/USP, 13 418-900, Piracicaba-SP, Brasil. gximena@esalq.usp.br

${ }^{3}$ Embrapa Mandioca e Fruticultura Tropical., Cruz das Almas-BA, Brasil. e-mail: macoelho@ cnpmf.embrapa. br;ecoelho@cnpmf.embrapa.br

${ }^{4}$ Professor doutor, NEAS, CCAAB, UFRB, Cruz das Almas-BA, Brasil.. e-mail: fadriano@ufrb.edu.br; vpspaz@ufrb.edu.br ${ }^{5}$ Professor doutor, CCAAB, UFRB, Cruz das Almas-BA, Brasil, e-mail: manoeltc@ufrb.edu.br
} 


\section{INTRODUÇÃO}

O conhecimento das necessidades hídricas das culturas é informação básica para a tomada de decisão e o bom uso conservação dos recursos hídricos em culturas irrigadas. Na prática da irrigação, as necessidades hídricas das culturas são estimadas com uso de coeficientes de cultivo e da determinação da evapotranspiração de referência (ETo), determinada por meio de estações meteorológicas, no mínimo, a partir de medidas tomadas por termômetros de máxima e mínima ou diretamente com evaporímetros tipo Tanque Classe A. O uso de coeficientes de cultivo, preconizados pela FAO (Allen et al., 1998), funciona muito bem para culturas anuais que cobrem completamente o terreno ou em cultivos irrigados por aspersão. Quando se trata de irrigação localizada, principalmente no caso do gotejamento, em que se minimizam as perdas de água por drenagem e evaporação na superfície do solo, grande parcela de água perde-se pela transpiração das plantas. Nesse caso, o conhecimento do volume de água utilizado pela planta (transpiração) é fundamental no auxílio para o manejo adequado de irrigação que, se bem aplicado, resultará em maior eficiência de uso de água e de fertilizantes, garantindo produtividade e redução no risco ambiental.

A quantificação da transpiração de fruteiras em campo é difícil e depende de muitos fatores, como a disponibilidade hídrica, as condições de demanda atmosférica, e fatores ligados à própria planta, como área foliar, geometria de copa e de plantio, que afetam a capacidade de interceptação da radiação solar e a interação com o vento (Angelocci, 1996; Valancogne et al., 2000). Atualmente, a utilização de métodos que se baseiam no fornecimento de calor ao caule das plantas (método de balanço calor caulinar (MBC), método de dissipação térmica (MDT) e o método de pulso de calor) vem proporcionando avanços no conhecimento das relações hídricas (Coelho Filho et al., 2005) e são bons subsídios para a estimativa da transpiração de fruteiras, como vêm demonstrando estudos visando ao estabelecimento de modelos simplificados que relacionam a transpiração com a área foliar e a evapotranspiração de referência (Coelho Filho et al., 2004., Coelho Filho et al., 2003; Angelocci et al., 1997). No caso da cultura do mamoeiro, foi demonstrada a possibilidade de se trabalhar com esses modelos em regiões úmidas e subúmidas (Coelho Filho et al, 2006), com ganhos em termos de produtividade e eficiência de uso de água, ao se utilizar o conhecimento da transpiração das plantas para o cálculo da lâmina de água, com base na ETo estimada por estação meteorológica automática e área foliar, segundo Coelho Filho et al. (2005).

No caso da cultura da manga, alguns estudos envolvendo os métodos térmicos para a quantificação do fluxo de seiva foram realizados (Lu \& Chacko, 1998; Coelho Filho et al., 2006) e evidenciaram bons resultados de estimativas do fluxo de seiva comparadas a transpiração medidas em lisímetros. Coelho Filho et al. (2006), trabalhando com lisímetros de pesagem, encontraram boa resposta dinâmica do MDT e subestimativas que devem ser corrigidas a fim de se quantificar a transpiração. Os mesmos autores, comparando o desempenho do MDT corrigido em nível de campo, observaram respostas dinâmicas semelhantes e concordância entre as estimativas usando MDT e MBC em plantas adultas de manga com ramos de 6 $\mathrm{cm}$ de diâmetro.

Como sistemas localizados de irrigação prevalecem na cultura da manga, nas regiões produtoras do semiárido, estudos básicos visando à modelagem da transpiração são muito úteis no auxílio ao manejo adequado de água nesses pomares. Principalmente, porque a área foliar é uma variável de entrada nesses modelos e é frequentemente alterada nas programações de podas para exposição de frutos, manutenção e adequação do tamanho da copa para posterior período de indução à floração. Como ainda se observa o uso inadequado da água em pomares de manga, com subjetividades nos cálculos das lâminas de irrigação, o presente trabalho visou a atender a carência de informação sobre o real consumo de água por plantas de manga. Considerando a transpiração como principal componente de uso de água em pomares irrigados por gotejamento, o presente trabalho avaliou as relações existentes entre a transpiração máxima, a evapotranspiração de referência e a área foliar, em quatro variedades de mangueiras: Tommy Atkins, Palmer, Haden e Van Dyke.

\section{MATERIAL E MÉTODOS}

O presente trabalho foi desenvolvido nos meses de março, abril e maio de 2003, na Embrapa Mandioca e Fruticultura Tropical, situada no município de Cruz das Almas-BA (1240’31' S, $39^{\circ} 05^{\prime} 17^{\prime}$ ' W e $225 \mathrm{~m}$ de altitude), em um pequeno pomar de manga com três anos de implantação, com quatro variedades: Tommy Atkins, Palmer, Haden e 
Van Dyke. O pomar foi irrigado por um sistema de irrigação por gotejamento, com seis gotejadores por planta e vazão média de $2,6 \mathrm{~L} \mathrm{~h}^{-1}$. A umidade do solo foi monitorada indiretamente pelas leituras de quatro tensiômetros instalados a $0,25 \mathrm{~m}$ de profundidade, sendo mantida sempre próxima à capacidade de campo, para que as plantas evapotranspirassem potencialmente (transpiração máxima).

Para cada variedade, foi escolhida uma planta, na qual foram instalados sensores para o monitoramento do fluxo de seiva (FS). O FS, nas quatro plantas estudadas, foi determinado com uso de sensores comerciais, modelos SAG13, SGB9, SGB16, SGB19, SGB25 (Dynamax Inc.), conectados a um sistema de aquisição de dados (CR10X, Campbell Sci), associado a um multiplexador (AM 416 Relay Multiplexer), para a ampliação dos canais disponíveis. As leituras foram realizadas a cada segundo, com valores médios armazenados a cada 20 minutos. Para cada uma das quatro variedades, foram selecionados cinco ramos da planta, dispostos nos sentidos norte $(\mathrm{N})$, sul $(\mathrm{S})$, leste $(\mathrm{E})$, oeste $(\mathrm{W})$ e centro (C). Cada ramo foi isolado termicamente do ambiente, de modo a receber apenas o calor fornecido pelo componente aquecedor do sensor ajustado à sua superfície, assim como realizado por Coelho Filho et al. (2005) em plantas de lima ácida 'Tahiti'. O fluxo de seiva, considerado como sendo a transpiração máxima da planta em 24 horas (Coelho Filho et al., 2005; Valancogne e Nars, 1993), foi calculado segundo o método do balanço de calor (Sakuratani (1981); Baker \& Van Bavel (1987):

$$
F=\frac{P_{i n}-Q_{V}-Q_{R}}{c_{P}-T}
$$

com base no método, o calor fornecido ao tronco $\left(\mathrm{P}_{\mathrm{in}}\right)$ é repartido $\left(P_{i n}=Q_{r}+Q_{v}+Q_{s}+Q_{f}\right.$ ) no segmento de caule aquecido em fluxos de calor (W) conduzidos pelo caule acima e abaixo do segmento $\left(Q_{v}\right)$, fluxo de calor que sai radialmente através do sensor $\left(\mathrm{Q}_{\mathrm{r}}\right)$, calor armazenado no segmento de caule $\left(Q_{\mathrm{s}}\right)$ e calor dissipado pelo aquecimento da seiva no segmento de caule $\left(Q_{\mathrm{f}}\right)$. Os fluxos axiais $\left(\mathrm{Q}_{\mathrm{v}}\right)$ foram estimados considerando-se a condutividade térmica do caule $\left(0,42 \mathrm{~W} \mathrm{~m}^{-1} \mathrm{~K}^{-1}\right)$ e os gradientes térmicos nas extremidades de segmento de caule amostrados, que foram medidos com termopares posicionados acima e abaixo da secção aquecida e em contato com o caule. Os fluxos radiais $\left(Q_{\mathrm{r}}\right)$ foram estimados a partir do conhecimento da condutividade térmica do substrato de cortiça $\left(\mathrm{K}_{\mathrm{sh}}\right)$, do qual é constituído o fluxímetro radial, com base na diferença de temperatura adjacente ao elemento aquecedor e da superfície externa da cortiça. O fluxo de seiva foi obtido dividindo-se o calor residual pelo calor específico da seiva $\left(c_{p}=4,186 \mathrm{~J} \mathrm{~g}^{-1} \mathrm{~K}^{-1}\right)$ e pela diferença de temperatura da seiva entre os limites superior e inferior do segmento aquecido $(\Delta \mathrm{T})$. Os valores de Ksh foram calculados diariamente, tomando-se a média do período de 4 a 5 horas, considerando que, nesse período, o fluxo de seiva é nulo, e o termo Qr é o resíduo da equação de balanço. O calor armazenado no caule foi considerado desprezível, considerandose que os diâmetros dos caules ficaram abaixo de 0,03m (Coelho Filho et al., 2005).

Para cada ramo estudado, foi calculada a sua área foliar total (AFT $-\mathrm{m}^{2}$ ) para a comparação padronizada dos resultados ao relacionar-se o FS e a área foliar $\left(\mathrm{L} \mathrm{m}^{-2}\right.$ folha/dia $\left.{ }^{-1}\right)$. A quantificação da AFT dos ramos foi realizada pelo somatório das superfícies de cada folha do ramo, calculadas com as medidas de maior e menor comprimento de todas as folhas do ramo avaliado. As relações entre as medidas de comprimento foliar (maior e menor) e a superfície foliar foram desenvolvidas por Oliveira et al. (2004), para cada variedade estudada. A área foliar total de cada planta foi quantificada utilizando a superfície foliar média das folhas da planta (média obtida com as folhas dos ramos em que foram instalados sensores para a determinação do fluxo de seiva) multiplicada pelo número total de folhas da mesma.

A transpiração máxima total de cada uma das plantas foi calculada, para cada dia, multiplicando-se a transpiração por unidade de área foliar média $\left(\mathrm{L} \mathrm{m}^{2}\right.$ folha $\mathrm{dia}^{-1}$ ) da planta no dia, pela área foliar total da planta.

A estimativa da evapotranspiração de referência (ETo), segundo Allen et al. (1998), foi realizada a partir dos dados de uma estação meteorológica automática, instalada no campo experimental da Embrapa Mandioca e Fruticultura Tropical.

\section{RESULTADOS E DISCUSSÃO}

Os resultados referentes aos valores médios das medidas de área foliar obtidos para cada ramo das variedades Tommy Atkins, Palmer, Haden e Van Dyke, e área foliar total de cada planta encontram-se na Tabela 1. Observou-se variação nos valores de área foliar em cada ramo. Isto ocorreu em função de os ramos serem escolhidos de acordo com a necessidade de orientação de instalação do sensor, visando à obtenção de valores médios de fluxo de seiva representativos de toda planta. A área foliar total (AFT) das plantas também variou muito, de 7,62 
a $32,59 \mathrm{~m}^{2}$, dependendo da variedade estudada (Tabela 1), o que pode ser comprovado pela Figura 1 , na qual se observa a silhueta de as plantas avaliadas.

Apesar da grande variação no número de folhas nos ramos das plantas e de as plantas serem de variedades diferentes, existiu relação linear entre a área foliar total da planta $\left(\mathrm{m}^{2}\right)$ e a média da transpiração máxima estimada $\left(\mathrm{L} \mathrm{dia}^{-1}\right)$ no período avaliado (Figura 2). Esse resultado mostra o aumento proporcional da transpiração com a área foliar total da planta, sendo que a transpiração por unidade foliar $\left(\mathrm{L} \mathrm{m}^{-2}\right.$ dia $\left.^{-1}\right)$ variou em média de 1,58 ao longo do período estudado (Figura 2). Como a variação foi linear, independentemente da variedade e tamanho de plantas, é um bom indicativo de que esses resultados poderão ser usados como referência na prática de irrigação.

A evapotranspiração de referência (ETo) variou de 1,86 a 4,65 $\mathrm{mm} \mathrm{dia}^{-1}$ durante o período de estudo, sendo que o fluxo de seiva (transpiração) determinada nos ramos variou de $0,36 \mathrm{~L} \mathrm{~m}^{2}$ folha ${ }^{-1}$ $\mathrm{dia}^{-1}$ a 3,00 $\mathrm{L} \mathrm{m}^{2}$ folha ${ }^{-1} \mathrm{dia}^{-1}$ (Tabela 2), próximo dos valores obtidos por Coelho Filho et al. (2003) para cultura do mamão $(0,26$ a 3,06) e mínimos obtidos para lima ácida adulta e jovem $(0,20$ e 0,26, respectivamente) como relatado por Coelho Filho et al. (2004). Se considerada a maioria dos valores obtidos no presente estudo (Tabela 2), a transpiração ficou dentro do que foi observado por Coelho Filho et al. (2004), até $2,5 \mathrm{~L} \mathrm{~m}^{2}$ folha ${ }^{-1} \operatorname{dia}^{-1}$. A transpiração nos ramos foi proporcional, em média, à ETo determinada no período de medida para cada variedade estudada: Palmer, Tommy A., Haden e Van Dyke, respectivamente, de 3,06 $\mathrm{mm} \mathrm{dia}^{-1}, 3,3 \mathrm{~mm} \mathrm{dia}^{-1}$,

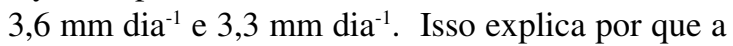
variedade Palmer transpirou menos por unidade folha, em média, 1,3 $\mathrm{L} \mathrm{m}^{2}$ folha ${ }^{-1} \mathrm{dia}^{-1}$, comparada às outras variedades cujos valores foram próximos (Tommy A. 1,57 L m folha $^{-1} \mathrm{dia}^{-1}$; Haden 1,96 $\mathrm{L} \mathrm{m}^{2}$ folha ${ }^{-1} \mathrm{dia}^{-1}$ e Van Dyke $1,78 \mathrm{~L} \mathrm{~m}^{2}$ folha ${ }^{-1} \mathrm{dia}^{-1}$ ).

Ao analisar-se as curvas diárias de transpiração (Figura 3), houve resposta dinâmica à radiação solar, proporcional à área foliar dos ramos, demonstrando que o método do balanço de calor funcionou adequadamente, sendo uma boa alternativa para estudos envolvendo relações hídricas em pomares de mangueira. Essa observação pode ser constatada claramente na Figura $3 b$, mangueira Palmer, quando, nos dois últimos dias avaliados, a ETo diminuiu de patamares próximos a 4 $\mathrm{mm} \mathrm{dia}{ }^{-1}$ para aproximadamente $2 \mathrm{~mm} \mathrm{dia}{ }^{-1}$, com reduções proporcionais do fluxo de seiva, mantendose as diferenças proporcionais de fluxo entre os ramos.
Quanto aos valores de fluxo de seiva por unidade de folha por ramo (Litros $\mathrm{m}^{2}$ folha ${ }^{-1} \mathrm{dia}^{-1}$ ) $\mathrm{Tr}$ $\mathrm{Rn}$, não foram verificados claramente os efeitos da maior ou menor densidade foliar, nem do posicionamento do ramo afetando os valores diários determinados. Analisando a Tabela 2, verifica-se que, se for comparada a transpiração por unidade foliar dos ramos com a maior e a menor área foliar, apenas para a variedade Palmer não ocorreu o esperado, ou seja, a maior transpiração por unidade de folha em ramos com menor densidade foliar. Porém, essa constatação não se mantém ao se analisarem-se todos os ramos. Verifica-se, pela Figura 4, que houve variações na transpiração por unidade de folha dos ramos, não sendo observada uma tendência clara do posicionamento do ramo nesses valores. Verificase, também, que os valores médios observados, independentemente do posicionamento e das variedades estudadas, ficaram próximos entre si.

Ainda com relação à transpiração por unidade de área foliar, Castro Neto (2003) observou que a transpiração, em ambos os lados da copa, tanto no lado exposto ao sol, quanto naquele exposto à sombra, apresentou a mesma tendência, afirmando que o efeito que provoca a redução na transpiração independe das condições de luminosidade em ambos os lados da copa da planta. Esse comportamento ainda reforça positivamente que os resultados dos volumes totais transpirados pela planta (que resultam dos valores médios dos ramos) são bem representativos, corroborando o que já havia sido verificado na Figura 2.

Apesar de não ser observada tendência muito clara ao avaliar-se os ramos individualmente, quando se trabalhou com valores médios de transpiração por unidade de área foliar, ao relacionarse transpiração $\left(\mathrm{L} \mathrm{m}^{2}\right.$ folha $\left.{ }^{-1} \mathrm{dia}^{-1}\right)$ com a evapotranspiração de referência estimada pelo método Penman-Monteith modificada pela FAO 56 (Figura 5), encontrou-se relação linear, com coeficiente angular de aproximadamente 0,44. Desta forma, é possível estimar a Transpiração da planta $\left(\mathrm{L} \mathrm{dia}^{-1}\right)$ a partir do conhecimento da área foliar da planta $\left(\mathrm{m}^{2}\right)$ e da ETo. Esse coeficiente é maior que o obtido para plantas jovens de lima ácida 'Tahiti' $(0,38)$ indicando uma condutância maior para as plantas de manga. No caso de mamoeiro, Coelho Filho et al. (2003) verificaram coeficientes de 0,56, explicados pela maior exposição solar das folhas destas plantas.

Avaliando-se a Figura 5b, observa-se que houve maior variabilidade ao trabalhar-se com os valores de transpiração de todos os ramos, mantendo-se o coeficiente angular. $\mathrm{O}$ mesmo ocorreu 
quando se relacionou a transpiração $\left(\mathrm{L} \mathrm{m}^{2}\right.$ folha ${ }^{-1}$ $\mathrm{dia}^{-1}$ ) com a radiação global, sendo que esta também se correlacionou linearmente com a transpiração por unidade folha, porém com correlação linear $\left(\mathrm{r}^{2}=0,70\right)$ e coeficiente angular $(0,093)$ menores.

Avaliando-se o coeficiente linear obtido para cada variedade separadamente, a partir dos valores médios de transpiração (Litros/planta/dia $\left.{ }^{-1}\right)$ e ETo de cada dia, houve variação de 0,40 a $0,45(0,41$ para
Tommy; 0,43 para Palmer; 0,45 para Haden; 0,40 para Van Dyke), o que mostra que, apesar das diferentes condições trabalhadas (área foliar e variedades avaliadas), o modelo médio é representativo e constitui-se numa boa alternativa para o manejo de irrigação por gotejamento, assim como verificado por Coelho Filho et al. (2006) para a cultura do mamoeiro.

TABELA 1- Área foliar total $\left(\mathrm{m}^{2}\right)$ de cada cinco ramos de quatro plantas de mangueira.

\begin{tabular}{lcccc}
\hline \multicolumn{1}{c}{ Ramo } & & \multicolumn{2}{c}{ Área Foliar $\left(\mathrm{m}^{2}\right)$} \\
& Tommy Atkins & Palmer & Haden & Van Dyke \\
\hline 1-leste & 0,26 & 0,39 & 0,94 & 0,48 \\
2-centro & 0,83 & 0,41 & 0,44 & 0,32 \\
3-oeste & 0,18 & 0,49 & 1,00 & 0,96 \\
4-norte & 0,58 & 0,68 & 0,98 & 1,58 \\
5-sul & 0,61 & 0,98 & 1,89 & 0,76 \\
AFT (Planta) & 14,44 & 7,62 & 32,59 & 12,16 \\
\hline
\end{tabular}

TABELA 2- Radiação solar (Rs), evapotranspiração por Penman-Monteith modificada pela FAO (ETo PMFAO), fluxo de seiva de cada ramo avaliado ( $\operatorname{Tr} \mathrm{R}-\mathrm{L} \mathrm{m}^{-2} \mathrm{dia}^{-1}$ ) e fluxo de seiva total da planta (Tr Pl - L dia $\left.{ }^{-1}\right)$, nos dias julianos avaliados (DJ).

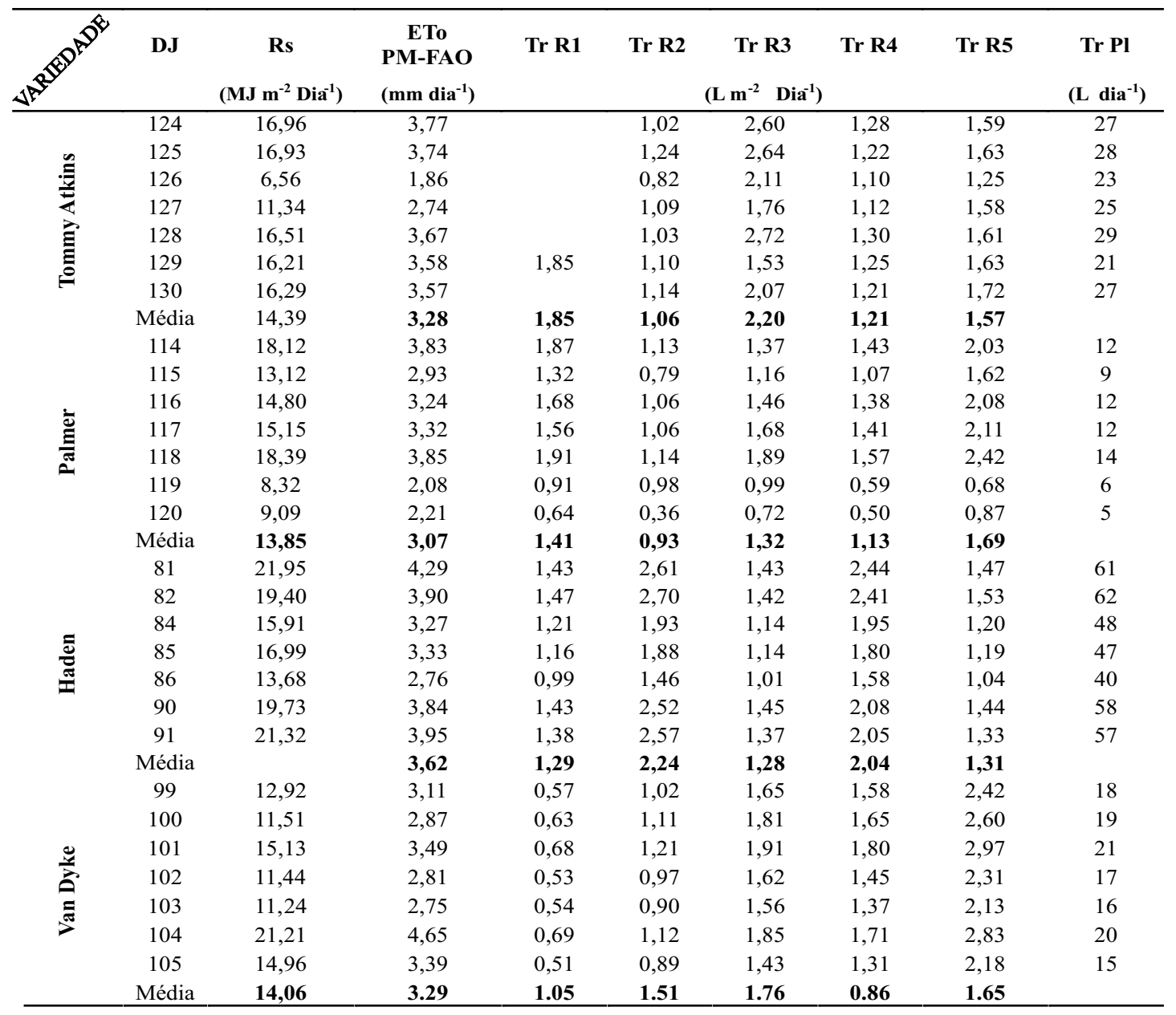



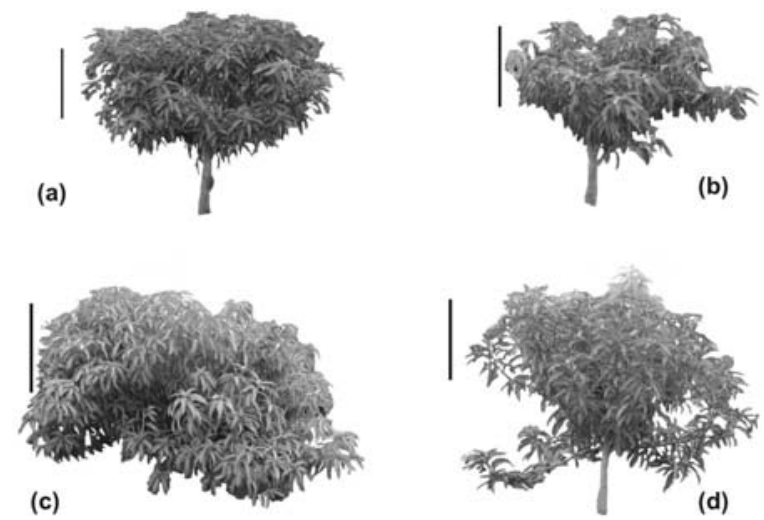

FIGURA 1- Silhueta das plantas jovens de mangueiras estudadas: (a) Tommy Atkins, (b) Palmer, (c) Haden, (d) Van Dyke. Escala de 0,80m.

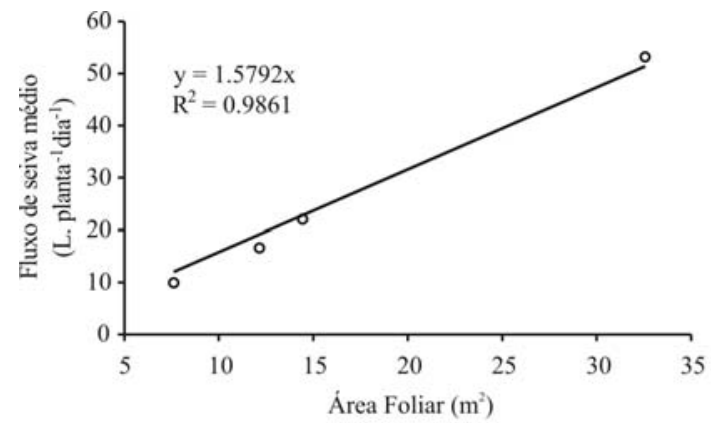

FIGURA 2 - Relação entre transpiração total média (Litros planta ${ }^{-1}$ dia $^{-1}$ ) para o período estudado e área foliar total das plantas.

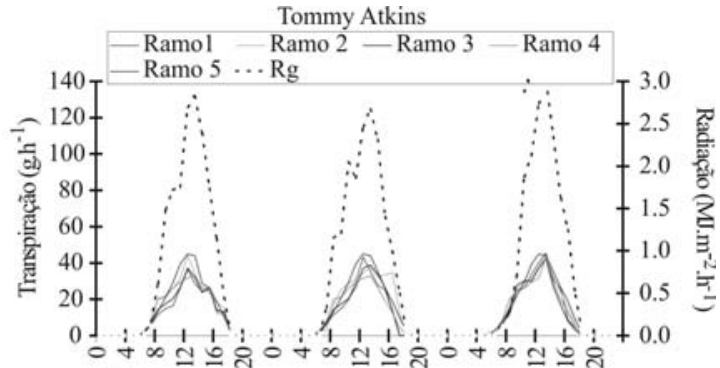

(a)

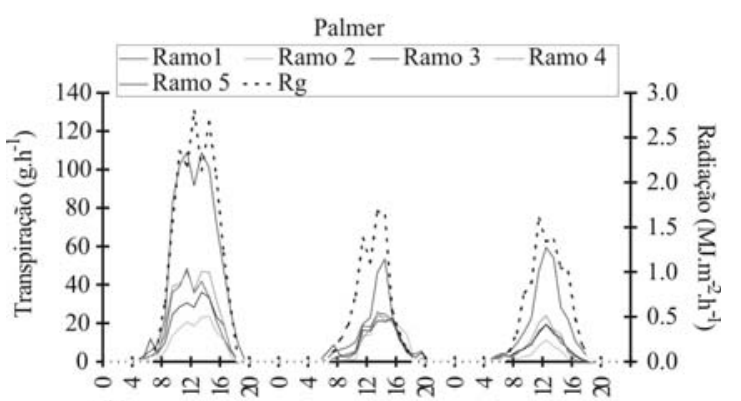

(b)

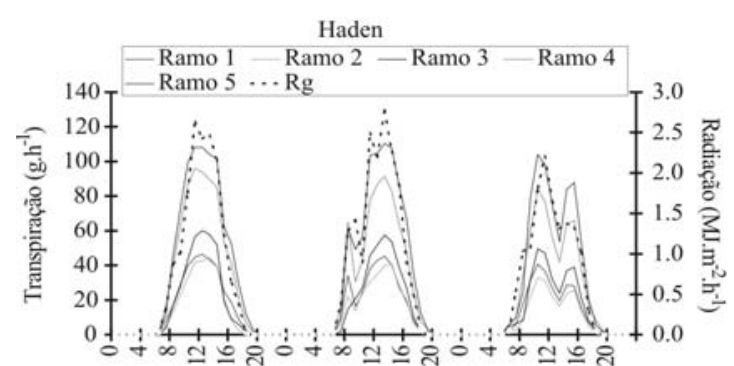

(c)

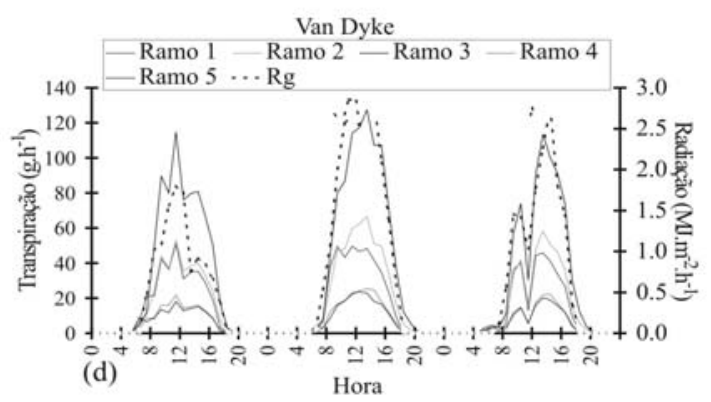

FIGURA 3 - Variação da radiação solar global $(\mathrm{Rg})$ durante três dias consecutivos e do fluxo de seiva estimados simultaneamente em cinco ramos de mangueira Tommy Atikins (a), Palmer (b), Haden (c) e Van Dyke, Cruz das Almas - BA, ano de 2003. 


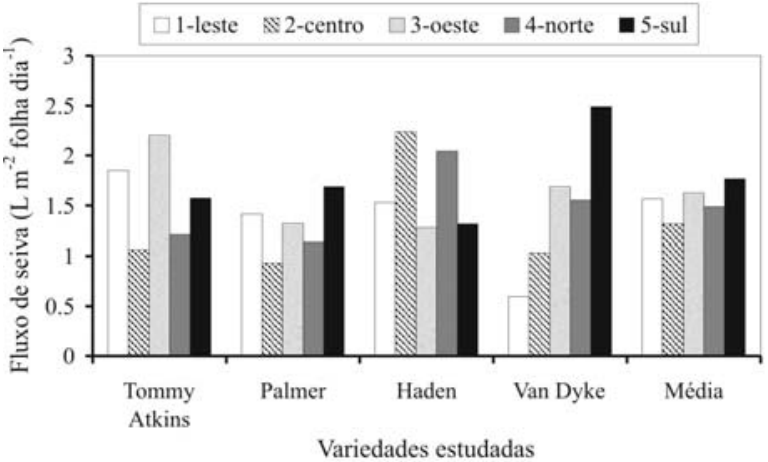

FIGURA 4- Fluxo de seiva $\left(\mathrm{L} \mathrm{m}^{-2}\right.$ folha dia $\left.^{-1}\right)$ médio de cada ramo avaliado para as quatro variedades de mangueira.
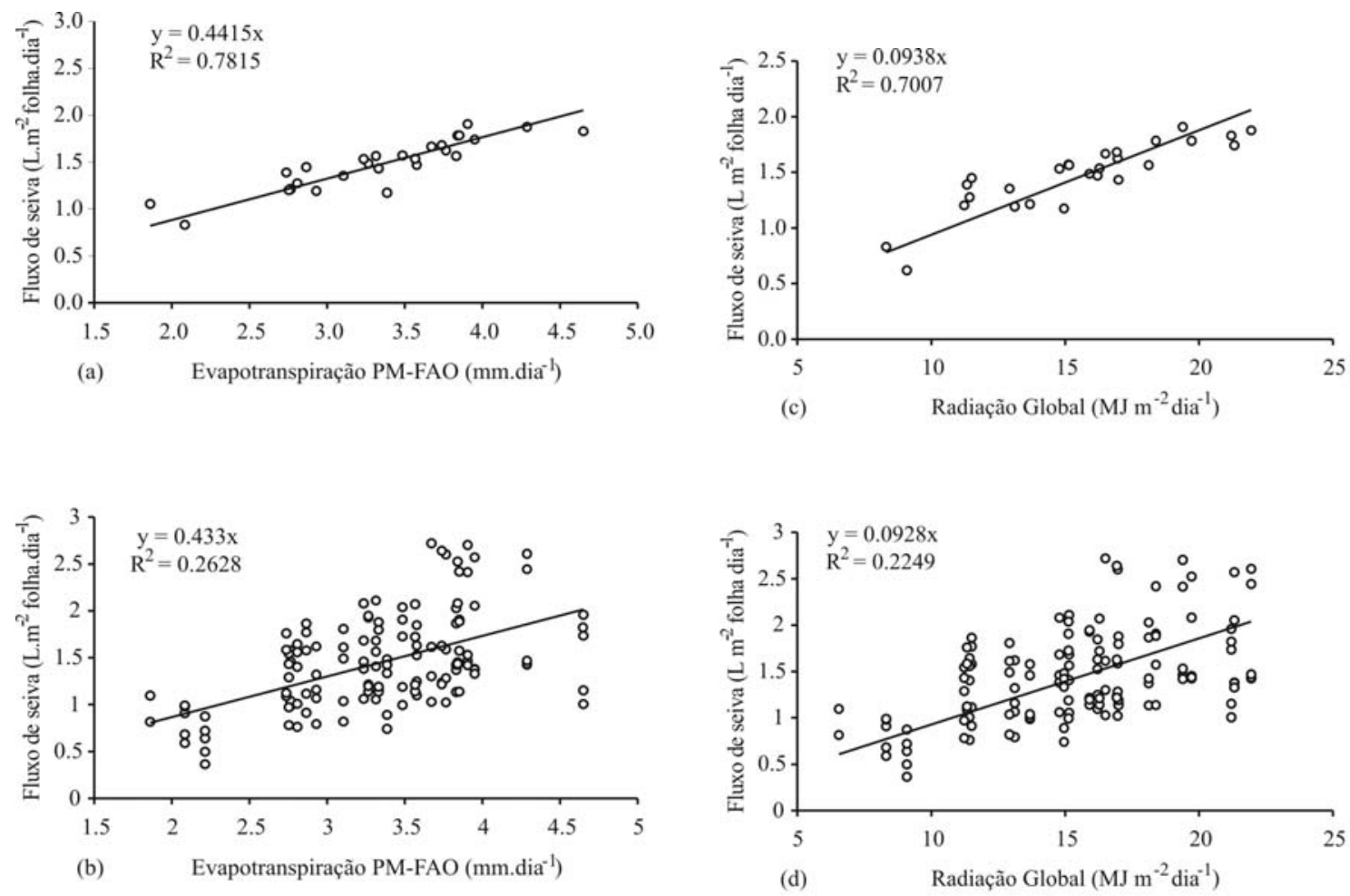

FIGURA 5- Relação entre o fluxo de seiva $\left(\mathrm{L} \mathrm{m}^{-2}\right.$ folha dia $\left.{ }^{-1}\right)$ de quatro variedades de mangueiras e a evapotranspiração de referência (ETo): Gráfico composto do fluxo de seiva $\left(\mathrm{L} \mathrm{m}^{-2}\right.$ folha dia $\left.{ }^{-1}\right)$ médio determinado nos ramos, em cada dia de medida (a); valores de fluxo de seiva de cada ramo estudado (b). Relação entre o fluxo de seiva $\left(\mathrm{L} \mathrm{m}^{-2}\right.$ folha dia $\left.{ }^{-1}\right)$ para quatro variedades de mangueiras e a Radiação Global: Gráfico composto pelo fluxo de seiva ( $\mathrm{L} \mathrm{m}^{-2}$ folha dia $\left.{ }^{-1}\right)$ médio determinado nos ramos, em cada dia de medida (c); valores de fluxo de seiva de cada ramo estudado (d). 


\section{CONCLUSÃO}

Considerando o fluxo de seiva determinado nas plantas como sendo a transpiração máxima, ficou comprovado que é possível a estimativa da transpiração ( $\mathrm{L} \mathrm{planta}^{-1}$ dia $^{-1}$ ) de plantas de manga mediante o conhecimento da Evapotranspiração de Referência (ETo - mm dia $\left.{ }^{-1}\right)$ e da área foliar $\left(\mathrm{m}^{2}\right)$ a partir da seguinte equação: Transpiração $=$ ETo . 0,44 . AF.

\section{REFERENCIAS}

ALLEN, R.G.; PEREIRA, L.S.; PAES, D.; SMITH, M. Crop evapotranspiration: guidelines for computing crop water requeriments. Rome: FAO, 1998. 300p. (Irrigation and drainage Paper, 56)

ALLEN, R. G. A penman for all seasons. Journal of Irrigation and Drainage Engineering. New York, v.112, p. 348-368, 1986.

ANGELOCCI, L.R. Estimativa da transpiração máxima de macieiras (Malus spp.) em pomares, pelo método de Penman-Monteith. Piracicaba, 1996. 71p. Tese (Livre-Docência)-ESALQ/USP.

ANGELOCCI, L.R.; VALANCOGNE, C.; VILLA NOVA, N.A.; PEREIRA, A.R. Relações entre fluxo de seiva de macieiras em pomar irrigado, área foliar e evapotranspiração de referência. In: CONGRESSO BRASILEIRO DE AGROMETEOROLOGIA, 10., Piracicaba, 1997. Anais. Piracicaba: SBA, 1997. p. 716718.

BAKER, J. M., VAN BAVEL, C. H. M. Measurement of mass flow of water in the stems of herbaceous plants. Plant, Cell and Environment, Oxford, v.10, p. 777-782,1987.

CASTRO NETO, M T. Efeito do déficit hídrico na transpiração e resistência estomática da mangueira. Revista Brasileira de Fruticultura, Brasil, Jaboticabal, v. 25, n. 1, p. 93-95, 2003.

COELHO FILHO, M. A. ; VELAME, Lucas Mello ; COELHO, E. F. ; PAZ, V. P. S. Uso de sensores de Granier para determinação da transpiração de mangueiras. In: CONGRESSO NACIONAL DE IRRIGAÇÃO E DRENAGEM, 16., 2006, Goiânia. Anais... Goiania: ABID, 2006.
COELHO FILHO M. A.; ANGELOCCI, L.R.; CAMPECHE, L.F.S.M.; FOLEGATTI, M. V.; BERNARDES, M. S. Field determination of young acid lime plants transpiration by the stem heat balance method. Sciencia Agrícola, Piracicaba, v. 62, n.3, p.240-247, 2005.

COELHO FILHO M. A.; ANGELOCCI, L.R.; ROJAS, J. S. D.; CAMPECHE, L.F.S.M.; FOLEGATTI, M. V. Relações entre transpiração máxima, área foliar e evapotranspiração de referência em pomar jovem de lima ácida 'Tahiti'. Revista Brasileira de Agrometeorologia, Santa Maria, v. 12, n.2, p.265-274, 2004.

COELHO FILHO, M.A.; CASTRO NETO, M.T.; COELHO, E.F. Transpiração máxima de plantas de mamão (Carica Papaya L.) em pomar fertirrigado, nas condições de Cruz das Almas BA. (compact disc) In: CONGRESSO NACIONAL DE IRRIGAÇÃO E DRENAGEM, 13., 2003, Juazeiro. Anais... Viçosa: ABID, 2003. CD-ROM

OLIVEIRA G. X. S.; PEREIRA, F. A. C; COELHO FILHO, M. A., COELHO, E.F. Avaliação de métodos não-destrutivos para a estimativa da área foliar de quatro variedades de mangueira. IN: CONGRESSO BRASILEIRO DE FRUTICULTURA, 18., 2004, Florianópolis. Anais... Florianópolis: SBF, 2004. CDROM

LU, P.; CHACKO, Evaluation of Granier's sap flux sensor in young mango trees. Agronomie, Paris, v.18, p. 461-471, 1998.

SAKURATANI, T. A heat balence method for mesuring water flux in the stem of intact plants. Journal Agricultural Meteorology, Amsterdam, v.37, n.1, p.9-17,1981.

VALANCOGNE, C.; NASR, Z. A heat balance method for measuring sap flow in small trees. In: BORGHETTI, M.; GRACE, J.; RASCHI, A. (Ed.). Water transport in plants under climatic stress. Cambridge: Cambridge University Press, 1993.p. 66-173. 